\title{
Establishment of a Novel Oral Murine Model of Ricin Intoxication and Efficacy Assessment of Ovine Ricin Antitoxins
}

\author{
Sarah J. Whitfield ${ }^{1, *}$, Debbie B. Padgen ${ }^{1}$, Simon Knight ${ }^{1}$, Robert J. Gwyther ${ }^{1}$, Jane L. Holley ${ }^{1}$, \\ Graeme C. Clark ${ }^{1,2}$ and A. Christopher Green ${ }^{1}$ \\ 1 CBR Division, Dstl-Porton Down, Salisbury SP4 0JQ, UK; dbpadgen@dstl.gov.uk (D.B.P.); \\ sjknight@dstl.gov.uk (S.K.); rjgwyther@dstl.gov.uk (R.J.G.); jlholley@dstl.gov.uk (J.L.H.); \\ gcclark@dstl.gov.uk (G.C.C.); acgreen@dstl.gov.uk (A.C.G.) \\ 2 Institute of Infection and Global Health, University of Liverpool, IC2 Building, Liverpool L3 5RF, UK \\ * Correspondence: sjwhitfield@dstl.gov.uk
}

Received: 4 November 2020; Accepted: 4 December 2020; Published: 8 December 2020

\begin{abstract}
Ricin, produced from the castor beans of Ricinus communis, is a cytotoxin that exerts its action by inactivating ribosomes and causing cell death. Accidental (e.g., ingestion of castor beans) and/or intentional (e.g., suicide) exposure to ricin through the oral route is an area of concern from a public health perspective and no current licensed medical interventions exist to protect from the action of the toxin. Therefore, we examined the oral toxicity of ricin in Balb/C mice and developed a robust food deprivation model of ricin oral intoxication that has enabled the assessment of potential antitoxin treatments. A lethal oral dose was identified and mice were found to succumb to the toxin within $48 \mathrm{~h}$ of exposure. We then examined whether a despeciated ovine $\mathrm{F}\left(\mathrm{ab}^{\prime}\right)_{2}$ antibody fragment, that had previously been demonstrated to protect mice from exposure to aerosolised ricin, could also protect against oral intoxication. Mice were challenged orally with an $\mathrm{LD}_{99}$ of ricin, and 89 and $44 \%$ of mice exposed to this otherwise lethal exposure survived after receiving either the parent anti-ricin $\operatorname{IgG}$ or $\mathrm{F}\left(\mathrm{ab}^{\prime}\right)_{2}$, respectively. Combined with our previous work, these results further highlight the benefit of ovine-derived polyclonal antibody antitoxin in providing post-exposure protection against ricin intoxication.
\end{abstract}

Keywords: Ricinus communis; ricin; ovine; antitoxin; antibody; IgG; $\mathrm{F}\left(\mathrm{ab}^{\prime}\right)_{2}$; murine; oral; post-exposure therapy

Key Contribution: This is the first time an antibody-based antitoxin has provided protection against a lethal model of oral ricin intoxication.

\section{Introduction}

Ricin is a 65 kilodalton (KDa) glycoprotein produced by the plant Ricinus communis. There are many cultivars of $R$. communis found throughout the world, with the large-scale production of the plant used for the commercial manufacture of castor oil for cosmetics, coatings, industrial and/or automotive applications and as a source of biodiesel [1,2]. There are two million tonnes of castor oil produced each year, with the waste mash of castor seeds after the oil extraction process being approximately $5 \%$ ricin by weight [3].

Ricin is a type 2 ribosome-inactivating protein (RIP-II) that consists of two peptide chains (Aand B-chains) linked by single disulphide bond. The mechanism by which ricin exerts its toxic effects is well documented and involves both chains performing defined roles to bring about cell death. Initially, the B-chain (RTB) binds to the plasma membrane of the target cell via carbohydrate galactose 
residues [4]. The toxin is then endocytosed within vesicles and traffics through the trans-Golgi network to the endoplasmic reticulum (ER) whereby the RTB and the catalytically-active A-chain (RTA) separate via reductive cleavage by protein disulphide isomerases (PDI) [5]. The A-chain (RTA) is then transported into the cytosol via the endoplasmic reticulum-associated protein degradation system (ERAD) where the RTA refolds and inhibits protein synthesis. Specifically, the RTA causes the depurination of the $\alpha$-sarcin-ricin loop (SRL) via the hydrolysis of the $\mathrm{N}$-glycosidic bond on adenine 4324 located on the $28 \mathrm{~S}$ rRNA ribosomal subunit resulting in a ribotoxic stress response [6]. This toxicity leads to direct cell membrane damage, the alteration of membrane structure and function, and the release of cytokine inflammatory mediators or apoptosis via multiple signalling pathways. Intoxication by ricin via most routes, including parenteral, inhalational and ingestion, can ultimately be lethal to man [7]. The estimated lethal doses for man have been extrapolated from experimental animal models and vary depending upon the route of exposure. However, the median lethal dose for ingestion is estimated to be around 1-20 mg per kilogram [7] and is around 1000 times more toxic via the inhalational and intravenous routes [8].

The cases of exposure of both humans and animals to ricin have been comprehensively reviewed by Worbs et al. [8]. Most reported cases relate to either accidental (e.g., animals eating R. communis plants, children chewing/eating castor beans) and/or intentional ingestions (e.g., suicide, prescribed by unlicensed health practitioners) [8]. Upon ingestion, non-specific symptoms of intoxication (e.g., diarrhoea, abdominal pain, vomiting, oropharyngeal pain) may take many hours to emerge [9-12] making early diagnosis challenging. The direct detection of the toxin in clinical samples (e.g., blood, stool) has also been found to be challenging even at high doses of purified ricin [8]. Reporting within experimental animal models of ingestion is limited but has shown increases in non-specific inflammatory markers such as TNF $\alpha$ [6]. This is followed by ricin-associated apoptosis and neutrophilic infiltrate into the intestinal tract, trafficking into and the collapse of the circulatory system and/or major organ failure leading to death [6,13-15]. Given these clinical challenges effective, treatments are urgently needed, as at present there are no licensed therapies available for ricin intoxication.

We have previously demonstrated the efficacy of a despeciated $\left(\mathrm{F}\left(\mathrm{ab}^{\prime}\right)_{2}\right)$ ovine polyclonal antitoxin which protected mice from a lethal ricin inhalational challenge as late as $24 \mathrm{~h}$ after intoxication [15]. The development of therapies to treat ricin intoxication continues to be an active area of research. Neutralizing antibodies (i.e., IgG and $\left.\mathrm{F}\left(\mathrm{ab}^{\prime}\right)_{2}\right)$ delivered shortly before or after intoxication have been shown to reduce or inhibit ricin induced toxicity in animal models [15-19]. Antibody-fragment based therapies for use in man are hypothesised to have a reduced incidence of adverse anaphylactoid or anaphylactic reactions following the single or repeat administration of antitoxin than the parent IgG antitoxins [15]. Given the obvious clinical challenges of diagnosing and treating ricin intoxication, we aimed to evaluate whether this antitoxin and the parent IgG antibody would also protect following the ingestion of ricin. We studied ricin ingestion in Balb/C mice using an approach that markedly reduced the time needed for food withdrawal, from $20 \mathrm{~h}$ to $8 \mathrm{~h}$, prior to ricin administration by oral gavage, thus providing ethical refinement over the previously published methods $[13,20,21]$.

\section{Results}

\subsection{A Food Withdrawal Time of $8 \mathrm{~h}$ Minimizes Variability in Stomach Contents}

Studies were undertaken to determine stomach and gut digesta clearance times in mice following the removal of food in order to generate a reproducible model in which to determine ricin oral toxicity and the efficacy of the ricin antitoxin. Mice were culled via cervical dislocation 4, 8, 10 or $11 \mathrm{~h}$ after food withdrawal. Comparative control mice were culled without food withdrawal at $0,4,8$ or $11 \mathrm{~h}$. The length of the empty small intestine between the stomach pylorus and visible digesta increased during the eleven hour time course in the food-deprived mice, with a significant difference observed at $11 \mathrm{~h}$ compared to the control mice given food ad libitum (Figure S1). Additionally, only residual digesta were observed within the stomach of the mice examined after $11 \mathrm{~h}$ (data not shown). There 
was a significant difference between the food-withdrawn and control mice in the wet weight of the large intestine at 8 and $11 \mathrm{~h}$ and in the small intestine after $11 \mathrm{~h}$. These observations suggest the digesta transit time through this region of the gastrointestinal tract is rapid in the BALB/c mouse with almost all the small intestine devoid of digesta at 10 and $11 \mathrm{~h}$ following food withdrawal. At $11 \mathrm{~h}$, adverse tail-biting behaviour was noted and the post mortem evidence of mouse bedding and corn cob ingestion was observed (data not shown). Due to these complications at $11 \mathrm{~h}$, the food withdrawal was reduced to $8 \mathrm{~h}$ to minimise the variability of the stomach contents within animals prior to ricin oral exposure.

\subsection{Toxicity of Orally Administered Ricin}

The challenge of Balb/C mice with oral doses of ricin ranging from 158 to $1564 \mu \mathrm{g} \cdot \mathrm{mouse}^{-1}$ resulted in dose-dependent, earlier times to death in the majority of mice. Four independent ricin dose-lethality studies were performed with the data analysed using Probit analysis (Minitab v17). No significant difference was seen between the studies ( $p=0.113$; chi square test) and the estimated $\mathrm{LD}_{50}$, was defined as the concentration of ricin expected to kill 50\% of the exposed population, which from the pooled data was $431.1 \mu \mathrm{g} \cdot$ mouse $^{-1}$ (95\% confidence interval (CI) 398.5-465.8 $\mu \mathrm{g} / \mathrm{mouse}$ ). The estimated LD 99 (the concentration of ricin expected to kill $99 \%$ of the exposed population) was $1050 \mu \mathrm{g} \cdot \mathrm{mouse}^{-1}$ (95\% CI 891.8-1332.0 $\mu \mathrm{g} / \mathrm{mouse}$ ) (Figure 1A,B).

Weight change profiles (Figure 1C) and signs of intoxication (piloerection, abdominal pinching and reduction in mobility) showed a dose-dependence, with mice receiving higher levels of toxin having more severe observed signs prior to death (Figure 1D). A route-specific sign of intoxication observed was a swollen abdomen and this was more prevalent for longer at lower doses of ricin (192 to $713 \mu \mathrm{g} \cdot$ mouse $\left.^{-1}\right)$. The occurrence of swollen abdomens in survivors was no longer observed by 10 days after oral gavage. At the highest doses of ricin $\left(949,1205\right.$ and $\left.1564 \mu \mathrm{g} \cdot \mathrm{mouse}^{-1}\right)$ lower occurrences were observed with the mice being killed at the humane endpoint or dying prior to the onset of this sign of intoxication (Figure 1E).

Subsequently, three replicate studies were performed on different days to verify the lethality of giving ricin at the $\operatorname{LD}_{99}\left(\sim 1050 \mu \mathrm{g} \cdot \mathrm{mouse}^{-1}\right)$ or Dulbecco's phosphate buffered saline (D-PBS) - administered to the negative control groups of mice ( $n=10$ per group). This dose resulted in the death of all mice within $69 \mathrm{~h}$ following challenge, with the mean time to death being $40 \mathrm{~h}$ (95\% CI 35.96 and 44.04) for the three studies (data not shown). The onset of signs of intoxication were evident $21 \mathrm{~h}$ after ricin challenge with mice showing increasing scores of piloerection and abdominal pinching prior to death. Additional signs included hunched posture (100\% of mice), a swollen abdomen ( $97 \%$ of mice) and watery eyes (90\% of mice).

The gross pathology within one group of 10 mice challenged with oral ricin (LD99) was compared with sham control groups receiving D-PBS $24 \mathrm{~h}$ after exposure (Figure 2). With the exception of the wet weight of the stomach and small intestine, which was significantly increased in ricin exposed mice compared to the sham control group, no significant differences in wet tissue weights were seen between treatment groups (Figure 2A). Unlike the control group, mice challenged with ricin had a distended stomach largely filled with food and the small intestine was enlarged, fluid-filled and showed signs of reddening. The large intestine was empty of digesta, with a third of mice showing signs of reddening and presence of fluid, indicating that the transit of digesta had slowed down/stopped following ricin administration (Figure 2B,C). Other consistent signs of intoxication in ricin challenged mice included kidneys appearing red and dark in colour and the liver appearing pale compared to the control mice (data not shown). 

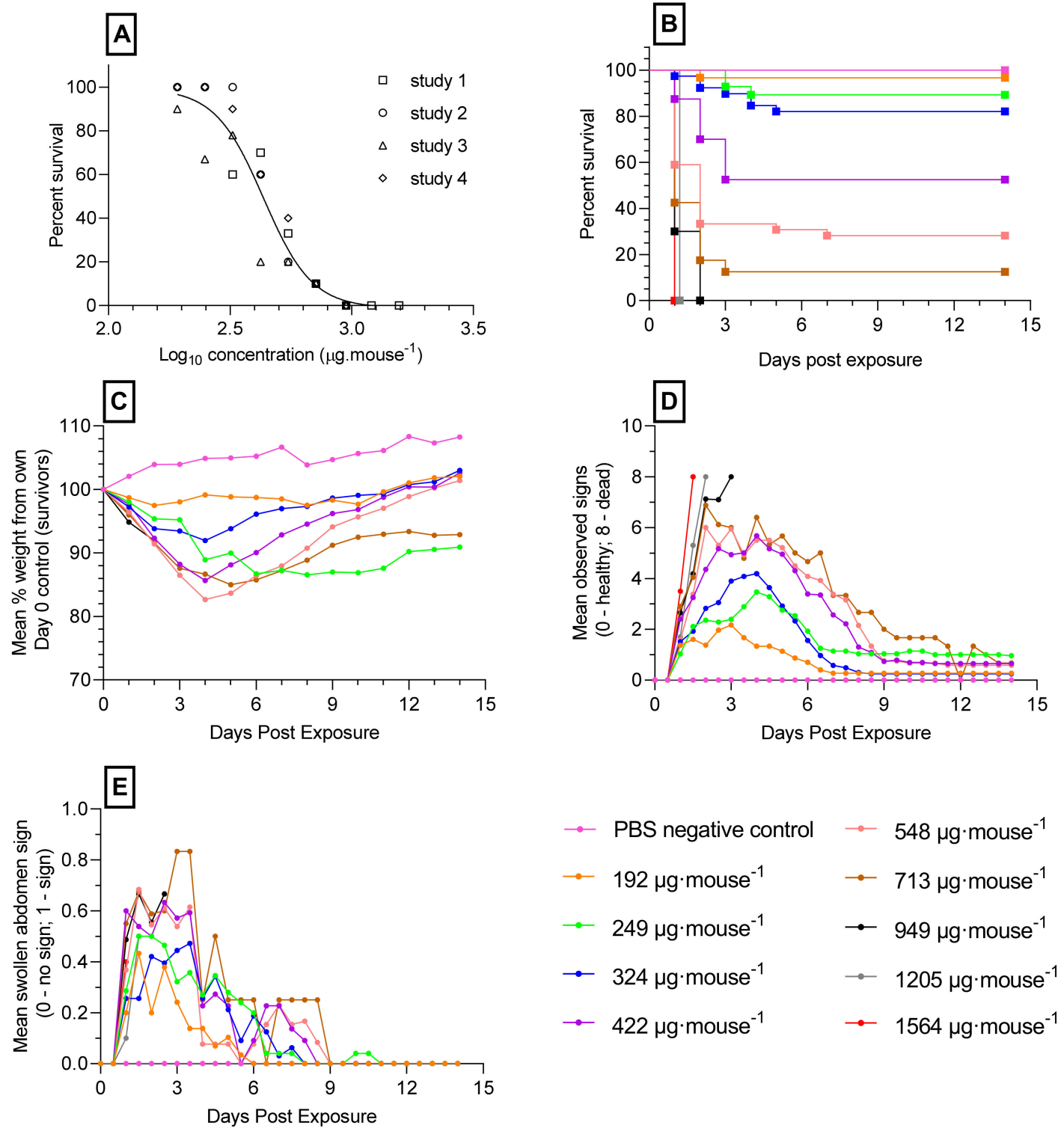

Figure 1. Survival and dose-response analysis $\left(\mathrm{LD}_{50}\right)$ of orally administered ricin in mice: (A) dose-response $\left(\mathrm{LD}_{50}\right)$ of orally administered ricin in Balb/C mice. Data points from four studies. (B) Kaplan-Meier survival plot; (C) mean bodyweight changes as a percentage of their own weight at 9 a.m. on day 0; (D) mean accumulative scores of signs of ricin intoxication (Table S1); (E) mean occurrences of route-specific signs of ricin intoxication over the 14 days (swollen abdomens) following ricin oral gavage. 

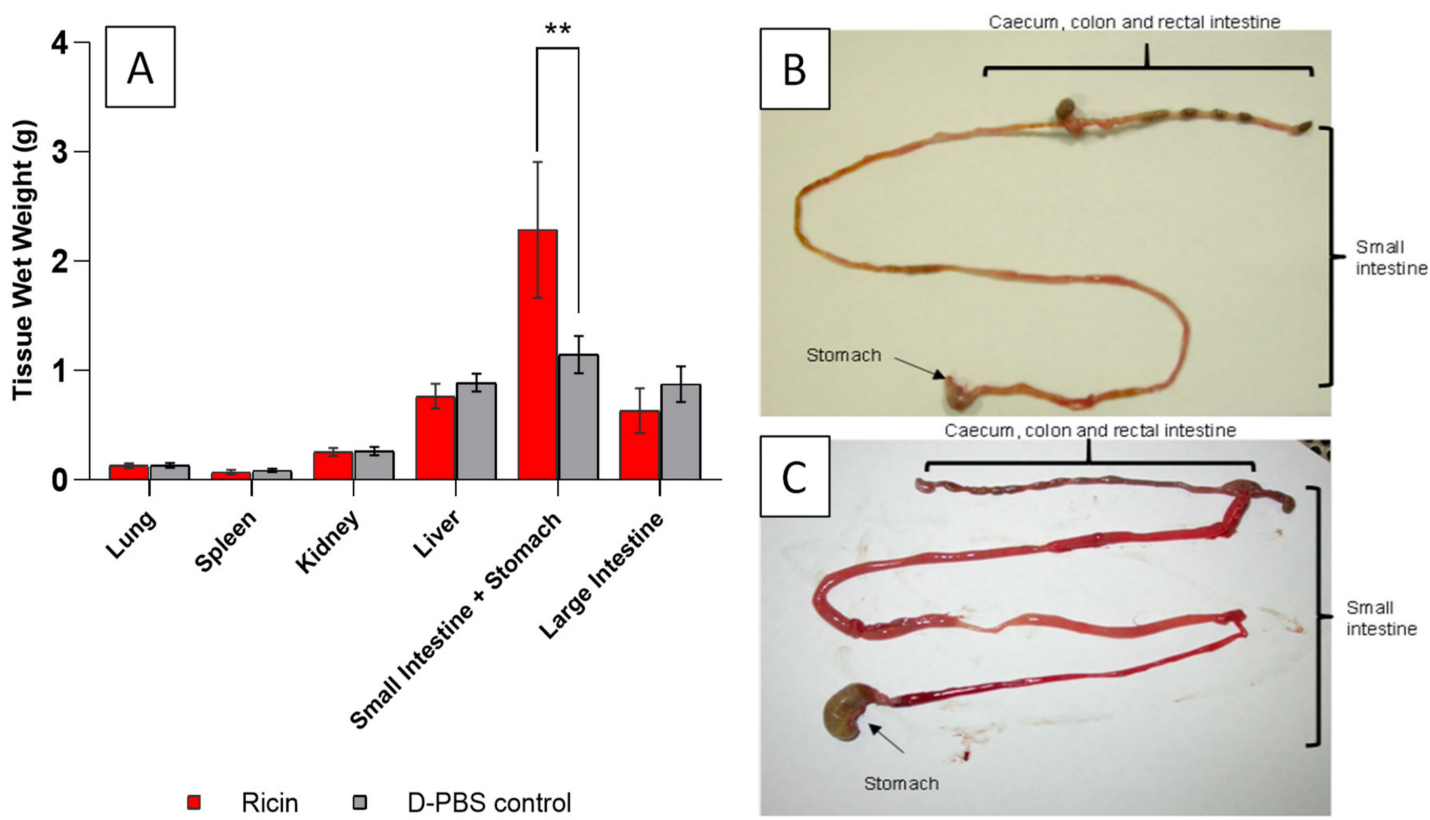

Figure 2. Gross pathological analysis of organs following lethal oral ricin exposure in mice. Post mortem pictures and tissue wet weight of Dulbecco's phosphate buffered saline (D-PBS) control mice (food withdrawn but no ricin) and those with food withdrawn and dosed with ricin at a concentration of $1050 \mu \mathrm{g} \cdot$ mouse $^{-1}$ by oral gavage. (A) Tissue wet weights. Data are shown as the mean \pm SD ( $n=29$ D-PBS and $n=30$ ricin dosed mice). The ricin dosed mice were found to have significantly heavier stomachs and smaller intestines than the controls (** $p=0.0014)$; (B and C) Pictures of the gastrointestinal (GI) tract of (B) control mice and (C) ricin dosed mice. The stomachs of the ricin dosed mice were full of food and the small intestine appeared reddened and fluid filled compared to the control mice.

\subsection{Ricin Antitoxin Increases Survival and Reduces Morbidity Following Orally Administered Ricin}

The efficacy of the ricin antitoxin against a ricin oral gavage was assessed. To evaluate the window of opportunity for effective antitoxin protection, the ricin antitoxin $\left(\mathrm{F}\left(\mathrm{ab}^{\prime}\right)_{2} ; 2.5 \mathrm{mg} \cdot\right.$ mouse $\left.^{-1}\right)$ was administered via the intravenous (iv) route at 1,3 or $5 \mathrm{~h}$ after an $\mathrm{LD}_{99}$ of ricin was administered by oral gavage. An antitoxin dose was selected that was previously found to be well tolerated by Balb/C mice and fully protective within a lethal aerosol ricin challenge in mice [12]. Mice given ricin followed by D-PBS $1 \mathrm{~h}$ after exposure (positive controls) succumbed to the effect of the toxin by three days after exposure, with $90 \%$ succumbing two days after exposure. An increase in survival and a reduction in morbidity was observed for the majority of mice administered ricin antitoxin (Figure $3 \mathrm{~A}$ ). At the experimental end point, 21 days after challenge, it was found that protection was afforded to 44,75 and $11 \%$ of mice that received a single bolus of antitoxin given at 1,3 , and $5 \mathrm{~h}$, respectively. Mice that were treated with antitoxin at 1 and $3 \mathrm{~h}$ showed a significantly increased survival compared to the untreated mice ( $p<0.004$ and 0.0001 respectively; Log-rank Mantel-Cox test). There was no significant improvement observed when treating mice with the ricin antitoxin at $5 \mathrm{~h}$. Weight loss profiles demonstrated a similar trend to that of survival profiles in that mice given antitoxin after 1 and $3 \mathrm{~h}$ resulted in a mean weight loss of less than $20 \%$, whereas a steeper decline $(30 \%)$ was observed in mice when antitoxin was given after $5 \mathrm{~h}$ (Figure 3B). Visible signs of ricin intoxication were observed in all mice given ricin oral gavage, with positive control mice displaying worsening signs of intoxication including piloerection, abdominal pinching and reduced mobility prior to succumbing to the effects of the toxin. A significant reduction in these observed signs was observed in mice given antitoxin at 1 , 3 and $5 \mathrm{~h}$, with the surviving mice recovering from ricin intoxication within 21 days after exposure (Figure 3C). 
A

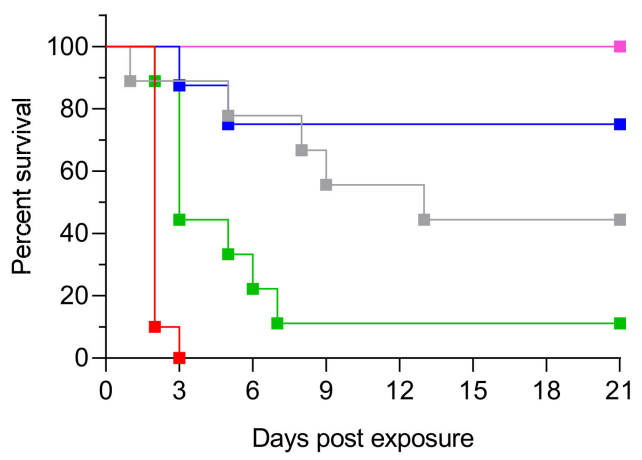

C

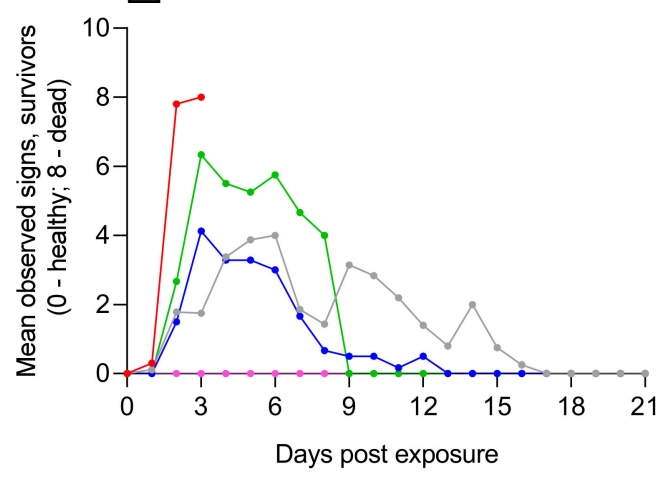

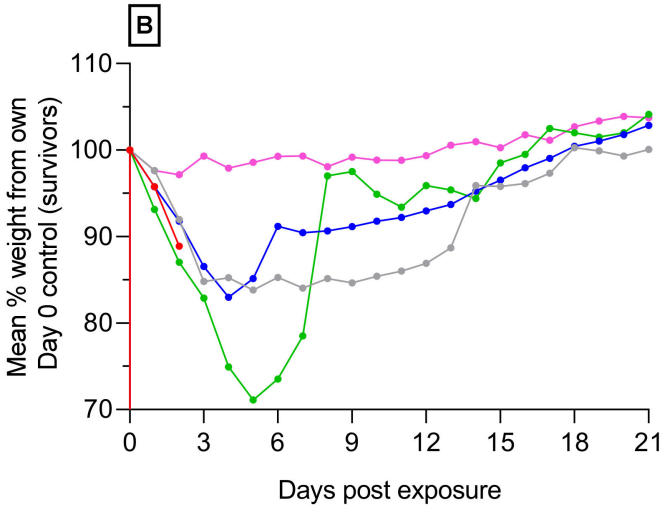

- Ricin only $(n=10)$

- Ricin antitoxin $\mathrm{F}\left(\mathrm{ab}^{\prime}\right)_{2}\left(2.5 \mathrm{mg} \cdot \mathrm{mouse}^{-1}\right) ; \mathrm{T}=1 \mathrm{~h}(n=9)$

- Ricin antitoxin $\mathrm{F}\left(\mathrm{ab}^{\prime}\right)_{2}\left(2.5 \mathrm{mg} \cdot \mathrm{mouse}^{-1}\right) ; \mathrm{T}=3 \mathrm{~h}(n=8)$

- Ricin antitoxin $\mathrm{F}\left(\mathrm{ab}^{\prime}\right)_{2}\left(2.5 \mathrm{mg} \cdot \mathrm{mouse}^{-1}\right) ; \mathrm{T}=5 \mathrm{~h}(n=9)$

- PBS negative control $(n=10)$

Figure 3. The window of opportunity for effective ricin antitoxin therapy following the oral exposure of Balb/C mice to ricin. A panel of graphs from a therapeutic window efficacy study in which $2.5 \mathrm{mg} \cdot$ mouse $^{-1}$ ricin antitoxin $\mathrm{F}\left(\mathrm{ab}^{\prime}\right)_{2}$ was administered to mice via the intravenous route (iv) at 1,3 or $5 \mathrm{~h}$ after a ricin challenge of $\sim 1050 \mu \mathrm{g} \cdot$ mouse $^{-1}$. (A) Kaplan-Meier survival plot; (B) mean bodyweight changes as a percentage of their own weight at 9 a.m. on day 0 ; and (C) mean accumulative scores of signs of ricin intoxication (Table S1).

A further study was performed to test the efficacy of the despeciated $F\left(a b^{\prime}\right)_{2}$ antitoxin compared to the parent IgG antibody against a lethal (LD99) oral challenge of ricin. Both antitoxins were administered intravenously $3 \mathrm{~h}$ after oral gavage of ricin (i.e., the time point that provided the greatest protection from orally administered ricin in the therapeutic window study). The potencies of both the whole IgG and the despeciated antibody were determined as previously described [15] to be 9.8 and $9.4 \mathrm{U} \cdot \mathrm{mg}^{-1}$ respectively. Each antitoxin was evaluated at two doses, the $\mathrm{F}\left(\mathrm{ab}^{\prime}\right)_{2}$ at $2.5 \mathrm{mg} \cdot \mathrm{mouse}^{-1}$, consistent with the previous protection studies, and at a higher dose of $5.0 \mathrm{mg} \cdot \mathrm{mouse}^{-1}\left(24\right.$ and $47 \mathrm{U} \cdot \mathrm{mouse}^{-1}$ respectively) to examine whether the dose of antitoxin had an effect on survival. The whole IgG parent molecule was delivered at 2.9 and $5.7 \mathrm{mg} \cdot$ mouse $^{-1}$ (28 and $57 \mathrm{U} \cdot \mathrm{mouse}^{-1}$, respectively) dosages in order to take into account the different molecular weights and neutralizing ratios of the antibodies. The administration of either antitoxin provided a significant survival benefit compared to untreated mice reducing mortality and delaying time to death after a ricin oral challenge (Figure 4A). The final survival rates seen for each group of mice were 44 and $33 \%$ following dosing with $\mathrm{F}\left(\mathrm{ab}^{\prime}\right)_{2}$ at 2.5 and $5.0 \mathrm{mg} \cdot \mathrm{mouse}^{-1}$, respectively. For the groups receiving whole IgG at 2.9 and $5.7 \mathrm{mg} \cdot \mathrm{mouse}^{-1}, 89$ and $80 \%$ was observed, respectively, after fourteen days of monitoring. There was no further advantage to increasing the dosage of the whole $\operatorname{IgG}$ or the $\mathrm{F}\left(\mathrm{ab}^{\prime}\right)_{2}$ antitoxin ( $p=<0.05$, Log-rank Mantel-Cox test). There was a significant difference in the degree of protection between the antitoxins IgG and $\mathrm{F}\left(\mathrm{ab}^{\prime}\right)_{2}$ with better protection seen in mice given the whole parent $\operatorname{IgG}(p<0.04$, Log-rank Mantel-Cox test). Weight loss profiles of mice showed that there was a similar response in mice given each antitoxin with a mean weight loss of less than $20 \%$, except for the $\mathrm{F}\left(\mathrm{ab}^{\prime}\right)_{2}$ at $5.0 \mathrm{mg} \cdot \mathrm{mouse} \mathrm{e}^{-1}$ where the mean 
weight loss was nearly $30 \%$ by day 8 (Figure $4 \mathrm{~B}$ ). Signs of intoxication showed dose dependence with a recovery of survivors by Day 14 (Figure 4 C).
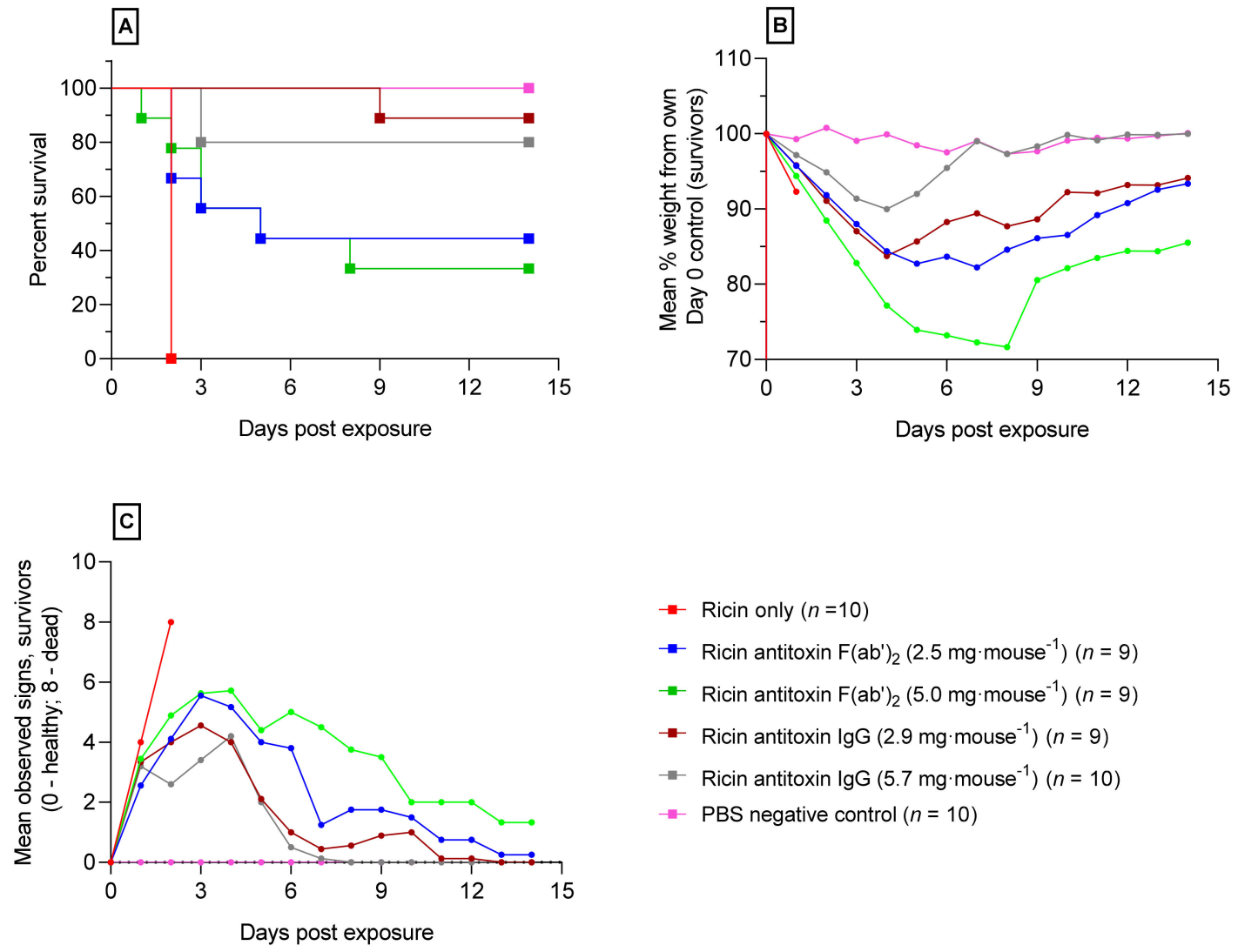

Figure 4. Comparison of the protective efficacy of anti-ricin toxin $\mathrm{F}\left(\mathrm{ab}^{\prime}\right)_{2}$ and the parent IgG polyclonal antibodies following the oral intoxication of mice. Both antibodies were administered to mice via the intravenous route (i.v.) $3 \mathrm{~h}$ after a lethal $\left(\mathrm{LD}_{99}\right)$ ricin challenge. (A) Kaplan-Meier survival plot; (B) mean bodyweight changes as a percentage of their own weight at 9 a.m. on day 0; and (C) mean cumulative scores of signs of ricin intoxication (Table S1).

\section{Discussion}

The common route of exposure to ricin in humans and animals is through the ingestion of the toxin either accidentally (e.g., consumption of castor beans containing ricin) or intentionally (e.g., suicide) $[8,11]$. Therefore, therapeutic approaches that offer any protection from the action of the toxin are required as at present only supportive and/or palliative care can be offered following intoxication. We have previously shown that an ovine-derived $\mathrm{F}\left(\mathrm{ab}^{\prime}\right)_{2}$ antitoxin was effective at preventing mortality and morbidity when given up to $30 \mathrm{~h}$ after a lethal inhaled ricin exposure [15]. Here, for the first time, we demonstrate the protective efficacy that the post-exposure administration of a single bolus of an antibody-based antitoxin can offer from oral ricin intoxication. We have developed and characterised a lethal murine oral model of ricin intoxication to assess the efficacy of a despeciated $\mathrm{F}\left(\mathrm{ab}^{\prime}\right)_{2}$ antitoxin. When administered to mice $3 \mathrm{~h}$ after a lethal ricin challenge the $\mathrm{F}\left(\mathrm{ab}^{\prime}\right)_{2}$ antitoxin and the whole IgG parent molecule delayed times to death and statistically significant improvements in survival rates, compared to the untreated control mice (all of which succumbed to the toxin within $48 \mathrm{~h}$ ), were observed. In addition, the surviving mice had no, or mild, visible signs of intoxication and had regained body weight to within $10 \%$ of their starting weight by day 14 , suggesting effective recovery following ricin intoxication.

In order to test the efficacy of the antitoxin, we developed and characterised a reproducible lethal mouse model of oral ricin intoxication. Previous studies have highlighted that the administration of 
purified toxin or castor bean extracts using liquid oral administration have lower toxicity values and/or have inconsistent lethality data from experimental models [13,21-23]. Our model—involving oral gavage of purified ricin to empty or near empty gastrointestinal tracts-represents the most stringent test of the efficacy of a therapy and the worst case scenario from a clinical perspective; demonstrated by the significant increases in small and large intestine wet weights relative to control animals.

Historically, food withdrawal periods reported in the open literature range between a period of $4 \mathrm{~h}$ to overnight $[13,21-23]$ for in vivo studies using mice where food withdrawal is required prior to oral ricin gavage. Smallshaw et al. [13] reported that not withdrawing food prior to oral gavage dosing led to inconsistencies in ricin toxicity values. This was attributed to presence of food in the stomach of the mice (in variable amounts) increasing the absorption of ricin into the food contents in the stomach, thereby reducing the toxicity. To achieve consistent data, Smallshaw et al. [13] developed a model where food was withdrawn $20 \mathrm{~h}$ prior to ricin oral gavage, with food not returned until $4 \mathrm{~h}$ after ricin oral gavage. In an effort to further build upon this model, we examined the effect of the time of food deprivation on the gastrointestinal tract to minimise the variability of the stomach contents in mice (over an $11 \mathrm{~h}$ time period) prior to ricin oral gavage. The ricin administration time point of $8 \mathrm{~h}$ after food withdrawal was selected as a suitable refinement compared to the previous literature for oral gavage [13]. It included a further $2 \mathrm{~h}$ food withdrawal period after toxin administration to allow time for ricin absorption within the gastrointestinal tract and was considered a refinement over previous models due to the limitation of adverse behaviours.

In the murine model of ricin intoxication developed here, the $\mathrm{LD}_{50}$ was $21.5 \mathrm{mg} \cdot \mathrm{kg}^{-1}$ and the $\mathrm{LD}_{99}$ was $52.5 \mathrm{mg} \cdot \mathrm{kg}^{-1}$ (assuming a $20 \mathrm{~g}$ body weight). These values are similar to the previously published oral toxicity data for ricin in various strains of mice, which ranged between 7.5 and $20 \mathrm{mg} \cdot \mathrm{kg}^{-1}$ [21-23]. Interestingly, these toxicity data differed significantly from those achieved in studies by Smallshaw et al. who reported an $\mathrm{LD}_{50}$ of only $10 \mu \mathrm{g} \cdot \mathrm{kg}^{-1}$ [13] in Swiss-Webster mice following $20 \mathrm{~h}$ food withdrawal. This difference is unlikely to be due to the strain of mouse used as Alyssa et al. has determined an $\mathrm{LD}_{50}$ of $9.4 \mathrm{mg} \cdot \mathrm{kg}^{-1}$ in the same strain [21]. The small differences between our data and previous literature estimates of toxicity [21-23] are likely due to the strain and sex of mouse used, the length of time for the removal of food (and water), and ricin cultivar used and differences in humane endpoints between studies.

In our ricin oral gavage studies, the survival and signs of intoxication were dose-dependent, with increasing signs of morbidity (i.e., degree of piloerection, abdominal pinching and reduction in mobility), and a reduction in times to humane endpoint (or succumbing to the effects of the toxin) with increasing ricin doses. Other observed signs of intoxication included laboured breathing and diarrhoea, similar to those seen following an inhaled exposure to ricin [15]. Interestingly, in these studies the stomach was largely filled with food, suggesting damage to the stomach pylorus thereby inhibiting food transit through the gastrointestinal tract. In addition, the small intestine appeared reddened and fluid filled and the wet weight of the small intestine plus the stomach was approximately double that of a food withdrawn control administered PBS by oral gavage. Mice were also observed to have swollen abdomens within $24 \mathrm{~h}$ of exposure to ricin oral gavage, which upon post mortem was found to contain red fluid (data not shown). These route-specific observations align to those seen by Alyssa et al. [21] and indicate vascular leakage as a result of lethal vascular collapse or distributive shock. Alyssa et al. [21] also reported that tracking the movement of a lethal dose of ricin over time found that it was routed via the kidneys and damage to the intestines was minimal. Similar symptoms of poisoning are seen in man following oral ricin ingestion, including vomiting, abdominal pain, hypotension, tachycardia, bloody diarrhoea progressing to substantial gastrointestinal fluid loss progressing to renal failure and death [10].

The ricin antitoxins evaluated here are a despeciated $\left(\mathrm{F}\left(\mathrm{ab}^{\prime}\right)_{2}\right)$ ovine polyclonal antibody and its parent IgG. As a mixed population of molecules, polyclonal antibodies have the potential to bind to multiple epitopes on the surface of ricin. Therefore, the antitoxin investigated here may bind to multiple regions on the toxin involved in cellular binding, uptake, trafficking and/or catalytic activity [15]. 
They were able to decrease the signs of oral ricin intoxication and reduce mortality in mice when they were given up to $3 \mathrm{~h}$ after ricin exposure. An extended time to death was seen in the majority of mice given antitoxin and partial protection of 44 and 75\% was obtained for mice administered antitoxin after 1 and $3 \mathrm{~h}$, respectively. Treatment with the antitoxin after $5 \mathrm{~h}$ led to a poorer outcome with greater weight loss and visible signs of intoxication and only one of the nine challenged mice surviving to the end of the study. For comparison, the therapeutic window for the treatment of an inhaled $\left(3 \times \mathrm{LCt}_{50} / 21.54 \mathrm{mg} \cdot \mathrm{min} \cdot \mathrm{m}^{-3}\right)$ ricin challenge with the same ricin antitoxin was $24 \mathrm{~h}$ with full protection seen at the dose of $2.5 \mathrm{mg} \cdot$ mouse $^{-1}$ [15]. One explanation for the shorter therapeutic window seen here could be the route of exposure and the different toxico-kinetics and-dynamics of ricin when mice are challenged via oral administration. For example, differences in the kinetics of exposure of key target organs, compared to inhalation exposure, may limit the window of opportunity for the effective neutralisation of ricin toxicity by the antitoxin. Protection would also be related to pharmacokinetics and the time of administration of the antitoxin, with these having to correspond to the absorption, distribution and cellular uptake of the ricin in order to enable the effective neutralisation of ricin toxicity. Whole IgG molecules have previously been demonstrated to have a longer residence time in circulation than a $\mathrm{F}\left(\mathrm{ab}^{\prime}\right)_{2}$ antibody fragment in mice [24,25]. The anti-ricin IgG should therefore be present for longer in the blood which would contribute to higher protection afforded from ricin intoxication. A further study was therefore performed to compare protection afforded by the $\mathrm{F}\left(\mathrm{ab}^{\prime}\right)_{2}$ antitoxin and its parent anti-ricin IgG which appears to support this hypothesis. It was found that there was significant improvement in protection afforded when the parent IgG was given rather than the $\mathrm{F}\left(\mathrm{ab}^{\prime}\right)_{2}$ antitoxin. Thus, the ricin $\mathrm{F}\left(\mathrm{ab}^{\prime}\right)_{2}$ antitoxin may not maintain sufficiently high concentrations in the blood for long enough periods of time to provide protection. However, in addition to their pharmacokinetic properties, antitoxin fragments may also be "despeciated" by the removal of the Fc portion of the IgG molecule. It is this part of the molecule that tends to be recognised as foreign and elicits host immune responses against the antibody. This host immune response can result in immediate adverse reactions following a single exposure (anaphylactoid) or anaphylactic reactions on subsequent (i.e., repeat) antitoxin administration [24,25].

The investigation of the formulation, route (e.g., encapsulation of the antibody and oral delivery) or duration (e.g., infusion rather than a bolus) of antitoxin delivery may further enhance the effectiveness of this therapy, ensuring the timely neutralisation of the toxin either within the gastrointestinal tract or over a longer period of time within the blood supply respectively. The confirmation of these hypotheses, however, would require additional toxicokinetic and pharmacokinetic studies.

Recent cases of human oral ricin ingestion have occurred as a result of either accidental poisonings or suicide attempts $[8,10]$. Collectively, from the research presented here, we demonstrated that neutralising antibodies or antibody fragments can reduce the effects of lethal oral ricin toxicity when administered shortly after intoxication. Protection was afforded despite our model representing the worst case scenario for intoxication (i.e., ricin exposure within an empty GI tract). Therefore, protection might be improved by either the early or multiple administrations of antitoxin in man alongside other supportive therapies. Ultimately, this work demonstrated, for the first time, that a single bolus of antibody therapy provided in a post-exposure context can still provide protection to mice from a lethal oral ricin intoxication.

\section{Materials and Methods}

\subsection{Ricin Toxin}

Ricin toxin was prepared from the seeds of Ricinus zanzibariensis using the method described previously [15]. Briefly, seeds were de-husked and the soft seed matter was homogenised in aqueous medium. The oil was removed and the material partially clarified by centrifugation, with final purification achieved using chromatography methods. Due to the relatively low oral toxicity of ricin, material prepared as described above required the concentration to achieve appropriate dose volumes. 
Two batches were concentrated for these studies using Sartorius ${ }^{\mathrm{TM}}$ Vivapore concentrators (7.5 KDa cut-off) (Thermo Fisher Scientific, Loughborough, UK) to give a final concentrations of $15 \mathrm{mg} \cdot \mathrm{mL}^{-1}$ and $20.8 \mathrm{mg} \cdot \mathrm{mL}^{-1}$ in phosphate buffered saline (PBS) pH 7.0-7.2 (Gibco, Thermo Fisher Scientific, Loughborough, UK). The toxin was aliquoted into smaller single use volumes $(1000 \mu \mathrm{L})$ and stored at $-80{ }^{\circ} \mathrm{C}$. The ricin purity was $>95 \%$ when assessed by SDS-PAGE and the quantification of Coomassie staining the gel (both Sigma Aldrich, Poole, UK). Prior to being used in oral efficacy studies, the toxicity of the concentrated ricin preparations was confirmed and compared to parent material using the in vitro cell cytotoxicity method described previously [15].

\subsection{Preparation of Ricin Antitoxins}

Ovine anti-ricin polyclonal $\mathrm{F}\left(\mathrm{ab}^{\prime}\right)_{2}$ was produced as previously described [15]. A polyclonal IgG from which the $\mathrm{F}\left(\mathrm{ab}^{\prime}\right)_{2}$ was prepared was also used in these studies. Briefly, sheep were immunised using ricin toxoid produced from the same ricin cultivar. Sheep plasma (weeks 32 and 34) was collected and further processed to yield polyclonal IgG. The purification and despeciation of the whole antitoxin was performed using pepsin digestion (Sigma Aldrich, Poole, UK) and antitoxins freeze dried for storage.

\subsection{Animal Husbandry}

Age-matched female Balb/c mice (6-7 weeks old; Charles River Laboratories Ltd., Margate, Kent, $\mathrm{UK}$ ) were used in all in vivo studies. Balb/c mice were used for practical, handling and behavioural reasons and female mice were used to avoid conflict between cage-mates. In addition, this approach maintained consistency with previously published studies in mice that assessed this antitoxin [15]. On receipt, the mice were habituated to the experimental animal unit for 5 days prior to use in the studies. All work was conducted in accordance with the Animals (Scientific) Procedures Act (ASPA), 1986 under project licence 30/3000 (Development of Medical Countermeasures for Licensure) using protocols 6 ( $\mathrm{LD}_{50}$ determination/toxin maintenance) and 3 (Efficacy testing of antitoxins). The Dstl Animal Welfare Ethical Review Board (AWERB) process was followed.

Mice were housed in rooms maintained at $21\left( \pm 2^{\circ} \mathrm{C}\right)$ on a $12 / 12 \mathrm{~h}$ dawn to dusk cycle. Humidity was maintained at $55( \pm 10 \%)$ with airflow of $15-18$ changes per hour and the mice were given food and water ab libitum except when food was withdrawn during studies. Mice were fed a standard pelleted Teklad TRM 19\% protein irradiated diet (Harlan Teklad, Bicester, UK). Mice were housed in groups of up to 10 mice.

\subsection{Minimisation of Variability after Oral Gavage into the Digestive Tract}

All time points selected for food withdrawal/fasting were below the $\mathrm{T}=16 \mathrm{~h}$ threshold for a licensable procedure under ASPA 1986, and shorter than other published methods [26-30]. These studies were necessary to ensure an ethical and robust food withdrawal protocol for use in all studies, allowing for a reproducible gut content volume prior to ricin oral gavage dosing for both $\mathrm{LD}_{50}$ oral toxicity and subsequent antitoxin efficacy studies. Groups of adult female Balb/c mice (17-21 g weight) ( $n=10-20$ per group) were permitted water ad libitum but deprived of food starting during their active dark phase (from 4 a.m., effective time $\mathrm{T}=0 \mathrm{~h}$ ). Mice were placed in clean cages, their body weight recorded and food withdrawn under nocturnal lighting so as not to disturb the animals' biorhythm [31,32]. Group sizes of $n=10-20$ were used following statistical advice from previous ricin toxicity sighting studies that had been undertaken (data not shown). Mice were culled by cervical dislocation at specific time points after food withdrawal $(T=4,6,8,10$ and $11 \mathrm{~h})$ to allow the determination of stomach content and weight, small and large intestine weights, and the determination of the clearance time for gut digesta from the stomach. All mice were monitored for adverse behavioural signs during the course of the experiment to ensure their wellbeing. A time period of $8 \mathrm{~h}$ was chosen between food withdrawal and ricin dosing with a further $2 \mathrm{~h}$ after dosing before food was returned, giving a total of $10 \mathrm{~h}$ food withdrawal. 


\subsection{Lethal Oral Model of Ricin Intoxication}

In order to orally administer ricin in solution to the mice, a disposable straight stainless steel gavage cannula (Harvard Apparatus IMS Ltd., Cambridge, UK) $(25 \mathrm{~mm} \times 20 \mathrm{~g})$ was used in conjunction with a $1 \mathrm{~mL}$ Luer lock syringe (Becton Dickinson, Swindon, UK). One gavage cannula and syringe was used per mouse. Each mouse was dosed with either ricin (200 $\mu \mathrm{L}$ in D-PBS) or with D-PBS as a vehicle control. The gavage cannula was gently introduced into the animal's mouth and carefully passed down the oesophagus to the stomach. The mouse was fully conscious throughout the procedure. The mice were observed every $30 \mathrm{~min}$ for the $2 \mathrm{~h}$ period following ricin dosing and prior to the return of food.

Mice undergoing toxicological and efficacy studies were monitored for signs of ricin intoxication and survival for up to 21 days. They were weighed daily at 9 a.m. and a range of observed signs of ricin intoxication were recorded twice daily ( 9 a.m. and 3 p.m.). These included piloerection, degree of abdominal pinching and changes in mobility, which were scored according to a graded scoring system (Table S1). A cumulative score based on piloerection (1-3) and abdominal pinching (1-3) was used in the figures. Once a score of 6 (score $=3$ for piloerection; score of 3 for abdominal pinching) had been reached a reduction in mobility was added to the piloerection scores (score of 7) and used as the endpoint (score of 8).

\subsection{Determination of Oral Toxicity of Ricin in Mice}

Four independent studies using up to 10 mice per ricin challenge dose were performed to determine the $\mathrm{LD}_{50}$ of orally administered ricin. Food was withdrawn $8 \mathrm{~h}$ prior to ricin dosing. The ricin was administered by oral gavage and mice were monitored for 14 days. Each $\mathrm{LD}_{50}$ study was performed on a separate day using data from the first study to direct the dose selection for studies 2-4.

\subsection{Confirmation of Ricin Challenge Dose for Use in Antitoxin Efficacy Studies}

Groups of up to 10 mice were dosed by oral gavage with either the $\mathrm{LD}_{99}$ ricin dose or D-PBS buffer (vehicle control) $8 \mathrm{~h}$ after food withdrawal. Food was returned $2 \mathrm{~h}$ after ricin administration. The mice in one ricin group were monitored until they met the humane end point or died. Mice in a second group were killed by cervical dislocation at $24 \mathrm{~h}$ and a post mortem examination performed with the wet weights of the key organs measured.

\subsection{Efficacy of Ricin Antitoxins against Lethal Oral Ricin Challenge}

The window of opportunity of the ricin antitoxin $\mathrm{F}\left(\mathrm{ab}^{\prime}\right)_{2}$ polyclonal antibody was evaluated using groups of up to 10 mice at 1,3 and $5 \mathrm{~h}$ following an $\mathrm{LD}_{99}$ dose of ricin, administered by the oral route. A subsequent efficacy study was performed to determine the efficacy of the antitoxin, both the parent $\operatorname{IgG}$ and the $\mathrm{F}\left(\mathrm{ab}^{\prime}\right)_{2}$ antitoxin in groups of up to 10 mice at $3 \mathrm{~h}$ following an $\mathrm{LD}_{99}$ dose of ricin. In both studies, the antitoxins were administered by an intravenous (i.v.) injection $\left(100 \mu \mathrm{L} \cdot\right.$ mouse $\left.^{-1}\right)$ into a tail vein. For window of opportunity studies, $\mathrm{F}\left(\mathrm{ab}^{\prime}\right)_{2}$ antitoxin was administered at a dose of $2.5 \mathrm{mg} \cdot$ mouse $^{-1}$. For the subsequent efficacy study, the parent IgG was given at doses of either 2.9 or $5.7 \mathrm{mg} \cdot$ mouse $^{-1}$ with the despeciated antitoxin given at doses of 2.5 or $5.0 \mathrm{mg} \cdot$ mouse $^{-1}$. The mice were monitored for up to 21 days after exposure. For negative controls, antitoxin vehicle (D-PBS) was administered i.v. $1 \mathrm{~h}$ following either a ricin or D-PBS oral challenge, respectively. All mice were weighed daily after exposure to orally administered ricin and visible signs of intoxication monitored at least twice daily.

\subsection{Data and Statistical Analysis}

The $\mathrm{LD}_{50}$ and $\mathrm{LD}_{99}$ for orally administered ricin intoxication were determined using the Probit analysis of the dose-response data with MiniTab v 17.0 (Coventry, UK). Data from these experiments were normalised to the control prior to the analysis. The replicates for each $\mathrm{LD}_{50}$ determination were pooled for final analysis. The equality of the toxicity curves was determined using a regression model 
with a comparison of the coefficients of each slope using a chi square test. For signs of intoxication, scores were generated on an accumulative basis for degrees of piloerection and abdominal pinching (Table S1) and survival, weights and signs were presented using GraphPad Prism for Windows v 8.0 (San Diego, CA, USA). A Log Rank (Mantel-Cox) test was performed to determine the significance between treatment groups in a window of opportunity and efficacy studies.

Supplementary Materials: The following are available online at http://www.mdpi.com/2072-6651/12/12/784/s1, Figure S1: Determination of organ wet weights and distance from stomach to digesta following period of food withdrawal: (A) position of digesta in the small intestine; (B) stomach wet weight as a percentage of mouse weight at $\mathrm{T}=0$; $(\mathrm{C})$ large and (D) small intestine wet weights following time culls post food withdrawal in female Balb/c mice; control groups of mice ( + food) did not have food withdrawn prior to cull (data are shown as mean \pm SD, $n=10-20)$; Table S1: Scoring of observable signs of ricin intoxication in the mouse. Signs of intoxication including piloerection and immobility, and abdominal pinching, were scored according to the descriptions in the tables. For the numerical scores recorded in the main figures, the sum of the piloerection and mobility and the abdominal pinching scores was used. Animals reaching a score of 5 on the piloerection and mobility scale were humanely killed (euthanised by a schedule 1 method).

Author Contributions: Conceptualization, J.L.H. and A.C.G.; methodology, S.J.W. and J.L.H.; software, R.J.G.; validation, J.L.H. and A.C.G.; formal analysis, S.J.W., J.L.H. and A.C.G.; investigation, S.J.W., D.B.P. and S.K.; resources, S.J.W., D.B.P. and S.K.; data curation, D.B.P., R.J.G. and S.J.W.; writing-Original draft preparation, S.J.W., D.B.P. and G.C.C.; writing-Review and editing, S.J.W., D.B.P., G.C.C. and A.C.G.; visualization, S.J.W., J.L.H. and A.C.G.; supervision, J.L.H. and A.C.G.; project administration, J.L.H. and A.C.G.; funding acquisition, J.L.H. and A.C.G. All authors have read and agreed to the published version of the manuscript.

Funding: This research was funded by the UK Ministry of Defence under contract STECH008.

Acknowledgments: The authors wish to acknowledge the Veterinary and Animal Service staff at Dstl for their professional support during this research.

Conflicts of Interest: The authors declare no conflict of interest.

\section{References}

1. Coppock, R.W.; Dziwenka, M. Potential Agents That Can Cause Contamination of Animal Feedstuffs and Terror. In Handbook of Toxicology of Chemical Warfare Agents, 2nd ed.; Academic Press: Cambridge, MA, USA, 2015; pp. 781-790.

2. Millard, C.B.; LeClaire, R.D. Ricin and Related Toxins: Review and Perspective. In Chemical Warfare Agents: Chemistry, Pharmacology, Toxicology, and Therapeutics, 2nd ed.; Romano, J.A., Jr., Lukey, B.J., Eds.; CRC Press: Boca Raton, FL, USA, 2007; pp. 423-467.

3. Hayoun, M.A.; Kong, E.L.; Smith, M.E.; King, K.C. Ricin Toxicity; StatPearls Publishing: Treasure Island, FL, USA, 2020.

4. Endo, Y.; Mitsui, K.; Motizuki, M.; Tsurigi, T. Mechanism of Action of Ricin and related Toxic Lectins on Eukaryotic ribosomes. J. Biochem. 1987, 262, 5908-5912.

5. Spooner, R.A.; Lord, J.M. Ricin trafficking in cells. Toxins 2015, 7, 49-65. [CrossRef] [PubMed]

6. Audi, J.; Benson, M.; Patel, M.; Schier, J.; Osterloh, J. Ricin poisoning: A comprehensive Review. JAMA 2005, 9, 2342-2351. [CrossRef] [PubMed]

7. Sowa-Rogzinska, N.; Sominka, H.; Nowakowska-Golacka, J.; Sandvig, K.; Slominska-Wojewodzka, M. Intracellular transport and cytotoxicity of the protein toxin ricin. Toxins 2019, 11, 350. [CrossRef] [PubMed]

8. Worbs, S.; Kohler, K.; Pauly, D.; Avondet, H.A.; Schaer, M.; Dorner, M.B.; Dorner, B.G. Ricinus communis intoxication in humans and veterinary medicine-A summary of real cases. Toxins 2011, 3, 1332-1372. [CrossRef] [PubMed]

9. Stankova, M.; Handlos, P.; Svidrnoch, M.; Maier, V. Fatal intoxication by intravenous injection of caster bean (Ricinus communis L) extract- a case study. Int. J. Legal Med. 2020, 134, 2133-2141. [CrossRef]

10. Benamor, M.; Gharbi, E.; Bouzid, S.; Chakroun-Walha, O.; Rekik, N. Ricin poisoning after oral ingestion of castor beans: A case report and literature review. Afr. J. Emerg. Med. 2020. In press. [CrossRef] 
11. Polito, L.; Bortolotti, M.; Battelli, M.G.; Calafato, G.; Bolognesi, A. Ricin: An Ancient Story for a Timeless Plant Toxin. Toxins 2019, 11, 324. [CrossRef]

12. Nunez, O.F.L.; Pizon, A.F.; Tamara, K. Ricin poisoning after oral ingestion of castor beans-A case report and review of literature and lab testing. J. Emerg. Med. 2017, 53, 67-71. [CrossRef]

13. Smallshaw, J.E.; Richardson, J.A.; Vitetta, E.S. RiVax, a recombinant ricin subunit vaccine, protects mice against ricin delivered by gavage or aerosol. Vaccine 2007, 25, 7459-7469. [CrossRef]

14. Bradberry, S. Ricin and Abrin. Chem. Terrorism. 2016, 44, 109-110. [CrossRef]

15. Whitfield, S.J.; Griffiths, G.; Jenner, D.; Gwyther, R.J.; Stahl, F.M.; Cork, L.; Holley, J.L.; Green, A.C.; Clark, G. Production, Characterisation and Testing of an Ovine Antitoxin against Ricin; Efficacy, Potency and Mechanisms of Action. Toxins 2017, 9, 329. [CrossRef] [PubMed]

16. Slyke, G.; Ehrbar, D.; Doering, J.; Yates, J.; Vitetta, E.; Donini, O.; Mantis, N. Endpoint and epitope-specific antibody responses as correlates of vaccine-mediated protection of mice against ricin toxin. Vaccine 2020, 38, 6721-6729. [CrossRef] [PubMed]

17. Falach, R.; Sapoznikov, A.; Evgy, Y.; Aftalion, M.; Makovitzki, A.; Agami, A.; Mimran, A.; Lerer, E.; Ben David, A.; Zichel, R.; et al. Post-Exposure Anti-Ricin Treatment Protects Swine Against Lethal Systemic and Pulmonary Exposures. Toxins 2020, 12, 354. [CrossRef]

18. Nydegger, U.E.; Sturzenegger, M. Adverse effects of intravenous immunoglobulinum therapy. Drug Saf. 1999, 21, 171-185. [CrossRef]

19. Rong, Y.; Pauly, M.; Guthals, A. A humanised monoclonal antibody cocktail to prevent Pulmonary Ricin Intoxication. Toxins 2020, 12, 215. [CrossRef]

20. Tshigaro, M.; Nakashima, H.; Tanabe, S.; Sakakibara, R. Interaction of toxic lectin Ricin with epithelial cells of rat small intestine in vitro. J. Pharm. Dyn. 1992, 40, 441-445.

21. Alyssa, D.F.; Teel, L.D.; Smith, M.A.; Sinclair, J.F.; Melton-Celsa, A.R.; O’Brien, A.D. Ricin Crosses Polarized Human Intestinal Cells and Intestines of Ricin-Gavaged Mice without Evident Damage and Then Disseminates to Mouse Kidneys. PLoS ONE 2013, 17, e69706.

22. Franz, D.R.; Jaax, N.K. Ricin toxin. In Medical Aspects of Chemical and Biological Warfare; Borden Institute, Walter Reed Army Medical Center: Washington, DC, USA, 1997; Chapter 32; pp. 631-642.

23. Balint, G.A. Ricin: The toxic protein of castor oil seeds. Toxicology 1974, 2, 77-102. [CrossRef]

24. Covell, D.G.; Barebt, J.; Holton, O.D.; Black, C.D.V.; Parker, R.J.; Weinstein, J.N. Pharmacokinetics of Monoclonal Immunoglobulin IgG1, $\mathrm{F}\left(\mathrm{ab}^{\prime}\right)_{2}$ and $\mathrm{Fab}^{\prime}$ in Mice. Cancer Res. 1986, 46, 3969-3978.

25. Bazin-Redureau, M.I.; Renard, C.B.; Scherrmann, J.M. Pharmacokinetics of heterologous and homologous immunoglobulin $\mathrm{G}, \mathrm{F}\left(\mathrm{ab}^{\prime}\right)_{2}$ and Fab after intravenous administration in the rat. J. Pharm. Pharm. 1997, 49, 277-281. [CrossRef] [PubMed]

26. Jensen, T.L.; Kiersgaard, M.K.; Sørensen, D.B.; Mikkelsen, L.F. Fasting of mice: A review. Lab. Anim. 2013, 47, 225-240. [CrossRef] [PubMed]

27. Strubelt, O.; Dost-Kempf, E.; Siegers, C.P.; Younes, M.; Volpel, M.; Preuss, U.; Dreckmann, J.G. The influence of fasting on the susceptibility of mice to hepatotoxic injury. Toxicol. Appl. Pharmacol. 1981, 60, 66-77. [CrossRef]

28. Hedric, H.J.; Bullock, G.R. The Laboratory Mouse; Elsevier Academic Press: Amsterdam, The Netherlands, 2004.

29. Kinoshita, M.; Igarashi, S.; Kume, E.; Saito, N.; Arakawa, K. Fasting induces impairment of gastric mucosal integrity in non-insulin-dependent diabetic $(\mathrm{db} / \mathrm{db})$ mice. Aliment. Pharm. 2000, 14, 359-366. [CrossRef] [PubMed]

30. Ellacott, K.L.J.; Morton, G.J.; Woods, S.C.; Tso, P.; Schwartz, M.W. Assessment of feeding behaviour in laboratory mice. Cell Metab. 2010, 12, 10-17. [CrossRef]

31. Froy, O.; Miskin, R. Interrelations among feeding, circadian rhythms and ageing. Prog. Neurobiol. 2007, 82, 142-150. [CrossRef] 
32. Noguchi, T.; Michihata, T.; Nakamura, W.; Takumi, T.; Shimizu, R.; Yamamoto, M.; Ikeda, M.; Ohmiya, Y.; Nakajima, Y. Dual-colour luciferase mouse directly demonstrates coupled expression of two clock genes. Biochemistry 2010, 49, 8053-8061. [CrossRef]

Publisher's Note: MDPI stays neutral with regard to jurisdictional claims in published maps and institutional affiliations.

(C) Crown copyright (2020), Defence Science and Technology Laboratory (Dstl). This material is licensed under the terms of the Open Government Licence except where otherwise stated.

To view this licence, visit: http://www.nationalarchives.gov.uk/doc/open-governmentlicence/version/3. 